\title{
Heat Pump Integration in a Cheese Factory
}

\author{
Helen Becker ${ }^{1 *}$, Aurélie Vuillermoz ${ }^{2}$, François Maréchal ${ }^{1}$ \\ ${ }^{1}$ Industrial Energy Systems Laboratory, Ecole Polytechnique Fédérale de Lausanne \\ ${ }^{2}$ EDF R\&D, Eco-efficiency and Industrial Process Department, Centre des Renardières \\ CH-1015 Lausanne, Switzerland, helen.becker@epfl.ch
}

The aim of this work is to increase the efficiency of industrial processes by using pinch analysis and process design methods. The main goals are the reduction of energy consumption, of the corresponding operating costs and of $\mathrm{CO}_{2}$ emissions. In this context heat pumps offer promising opportunities, when they are appropriately integrated into the process. Two different integration strategies can be applied: In a first approach, process modifications are not allowed whereas in a second approach it is possible to modify process units. It is shown that industrial and practical decisions have a big influence on the final choice of new equipments. The presented method is applied to a real case study in a cheese factory where both approaches are applied and compared. The results from the energy integration are analyzed and assessed with the practical feasibility of solutions.

\section{Introduction}

When studying the energy efficiency of an industrial process, the analysis of heat pump integration has to be considered as part of a complete methodology, beginning from the data collection and modeling of all process unit operations. In the food industry, most of the process operations are performed in batch mode. However, considering the temperature levels and the use of water as production support, the time average approach can be used to realize the process integration analysis. The use of pinch analysis techniques allows to identify heat recovery opportunities in the process while the grand composite curves shows the enthalpy temperature profile of the heat to be supplied to the process and of the heat excess to be evacuated by a cold utility. It allows also to identify opportunities for appropriate placements of utility systems such as heat pumping or refrigeration. Heat pump integration has been widely discussed in literature before 1990. For example, the rules for optimal placements of a heat pump in an industry process have been introduced by Linnhoff and Townsend (1983). Later, Wallin and Berntsson (1994) demonstrated that, characteristics of both, industrial process and heat pumps, must be taken into account. Kapustenko et al. (2008) analyzed heat pump integration based on selected streams of a cheese factory. Also Pavlas et al. (2010) analyzed heat pump integration for a gasification process. However both approaches are limited to ammonia refrigeration cycles. More generally, the potential of heat pumps is demonstrated by Becker et al. (2011). A mixed integer linear programming (MILP) formulation of the heat cascade is used to optimize simultaneously the flow rates in heat pumps and other utility systems. This paper analyzes two process integration options: First process modifications are not allowed and a newly 
integrated heat pump cannot exchange directly with the process. In the second option, process modifications and direct heat pump process integration are possible. Saving potential becomes higher, but also the complexity of process configurations increases.

\section{Example of cheese factory}

The industrial process that is used for this analysis (Figure 1a) is a cheese factory with several pasteurization units that are used to remove bacteria from milk, cream or water. The evaporation unit, one of the main consumers, consists in 5 effects and one thermal vapour compression. Before entering the evaporation in the first effect, the whey is first preheated to reach predefined operating conditions that leads to a first evaporation. Then, the remaining liquid is sent to the second effect at a lower pressure, and the vapour boiled off in the first effect is recovered to provide heat to the second effect. The same principle is valid for the following effects. A part of the steam from the third effect is reused in the thermal vapour compression (TVR) driven by high pressure steam. The remaining heating and cooling requirements concern process units like forming, product refining, packaging or cold stores. The energy consumption is expressed in $\mathrm{kWh}$ per tons of product. Currently $2895 \mathrm{kWh} /$ tprod of natural gas and $194 \mathrm{kWh} /$ tprod of electricity are consumed.

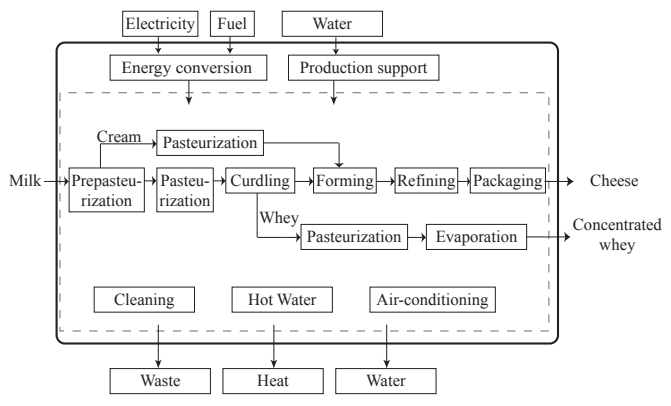

(a) Process description

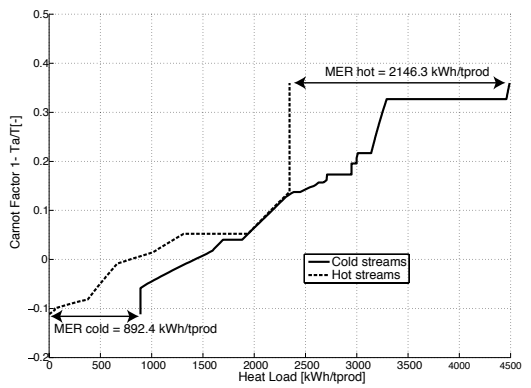

(b) Cold and hot composite curves

Figure 1: Process description and its hot and cold composite curves

\section{Methodology - process integration}

The analysis of process unit operations aims at defining the heating and cooling requirements to convert raw materials into products. In order to define heat recovery potentials, first the process hot and cold streams have to be defined. The streams of the evaporation units are modeled regarding the existing technology (5 effects with thermal vapour compression). The complete list of streams is reported in Table 1. Exergy losses can be visualized on Figure 1b, which shows the hot and cold Carnot composite curves. The process grand composite curve is presented in Figure 2a, while Figure 2b shows Case1, corresponding to the integrated current state of the process without heat pumping systems. 
Table 1: Process streams, $\Delta T_{\min / 2}$ values: $2.5^{\circ} \mathrm{C}$ (liquids), $1{ }^{\circ} \mathrm{C}$ (gases)

\begin{tabular}{|c|c|c|c|c|c|c|c|c|c|}
\hline Unit & Name & $\begin{array}{r}\text { Tin } \\
{\left[{ }^{\circ} \mathrm{C}\right]}\end{array}$ & $\begin{array}{l}\text { Tout } \\
{\left[{ }^{\circ} \mathrm{C}\right]}\end{array}$ & $\begin{array}{l}\text { Heat load } \\
{[\mathrm{kWh} / \mathrm{tp}]}\end{array}$ & Unit & Name & $\begin{array}{r}\text { Tin } \\
{\left[{ }^{\circ} \mathrm{C}\right]}\end{array}$ & $\begin{array}{l}\text { Tout } \\
{\left[{ }^{\circ} \mathrm{C}\right]}\end{array}$ & $\begin{array}{l}\text { Heat load } \\
{[\mathrm{kWh} / \mathrm{tp}]}\end{array}$ \\
\hline \multirow{3}{*}{ other } & other_c1 & 100 & 190 & 367.8 & \multirow{2}{*}{ pasto3 } & pasto3_c1 & 74 & 80 & 84.1 \\
\hline & other_h1 & 5 & 0.5 & 307 & & pasto3_c2 & 6 & 28 & 308.2 \\
\hline & other_h2 & -0.3 & -2.5 & 56.9 & \multirow{2}{*}{ pasto4 } & pasto4_c1 & 69 & 75 & 32.1 \\
\hline \multirow{4}{*}{$\begin{array}{l}\text { evapo } \\
\text { tech }\end{array}$} & evapo_c1 & 100 & 190 & 993.7 & & pasto4_c2 & 8.5 & 26 & 83.3 \\
\hline & evapo_h1 & 44 & 5 & 32.9 & pasto5 & pasto5_c1 & 66 & 76 & 54.2 \\
\hline & evapo_h2 & 44 & 25 & 198.1 & \multirow{3}{*}{ proc6 } & proc6_c1 & 105 & 105 & 131 \\
\hline & evapo_h3 & 44 & 44 & 627.8 & & proc6_c2 & 78 & 78 & 49.6 \\
\hline \multirow{3}{*}{ pasto1 } & pasto1_c1 & 6 & 48 & 568.2 & & proc6_c3 & 95 & 95 & 49.6 \\
\hline & pasto1_c2 & 48 & 75 & 344 & proc7 & proc7_c1 & 15 & 55 & 40.4 \\
\hline & pasto1_h1 & 75 & 4 & 904.6 & proc8 & proc8_c1 & 70 & 70 & 62.6 \\
\hline \multirow{2}{*}{ pasto2 } & pasto2_c1 & 79 & 85 & 5 & proc9 & proc9_c1 & 35 & 35 & 33.8 \\
\hline & pasto2_h1 & 54 & 4 & 41.9 & proc 10 & proc10_c1 & 32 & 25 & 175.5 \\
\hline heat & heat_c1 & 35 & 35 & 153 & CIP & clean_c1 & 85 & 85 & 238 \\
\hline
\end{tabular}

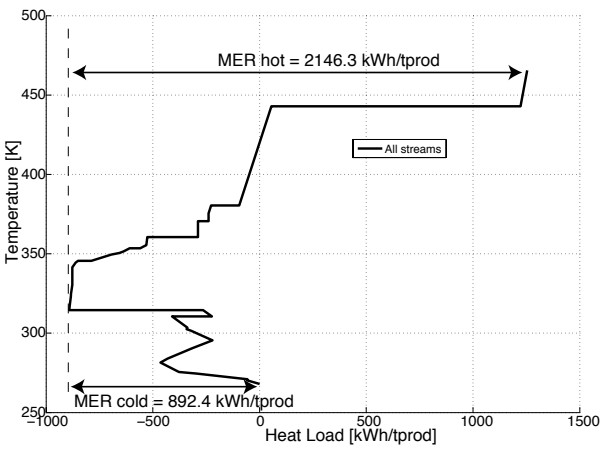

(a) Grand composite curve

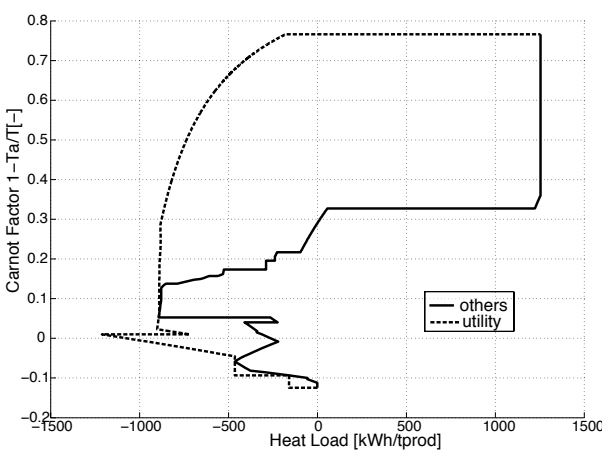

(b) Integrated composite curves (Case1)

Figure 2: Grand composite curve of the process and integrated composite curve of the utility system using Carnot scale.

\subsection{Heat pump integration option 1: No process modifications allowed}

Heat pumps are used to valorize waste heat from the process below the pinch point by driving it above the pinch point with the help of mechanical power, reducing therefore hot and cold utility requirements. In the first approach, the process can not be modified. Thus, the direct heat exchange between a potential heat pump and the process is not allowed. The approach from Becker et al. (2010) is applied: two sub-systems (in this case the process and the heat pump) cannot exchange heat directly. A closed cycle heat pump using the refrigerant R245fa is considered. By analyzing the shape of the grand composite curve, appropriate operating conditions for the heat pump and the intermediate network can be estimated. Then, simultaneously the interdependent flow rates of the utility units, heat pumps and the heat distribution fluids are defined, in order to minimize the operating costs. The potential of a closed cycle heat pump without direct heat exchange is illustrated 
in Figure 3a. The saving potential can be increased by minimizing the minimum temperature difference in the heat exchangers between the heat pump and the intermediate heat transfer fluids. The advantage of this approach is that only the investment costs related to the heat pump, heat exchangers and tubes for heat transfer have to be accounted without modifying the process itself. Also safety and product quality aspects are maintained. The results of this first approach are given in column "Case2" of Table 2.

\subsection{Heat pump integration option 2: Process modifications allowed}

In the second approach, process modifications are allowed. This leads to more heat pump integration opportunities. For example, operating pressures of the process can be modified to improve heat recovery, and mechanical vapour recompression (MVR) units can replace the thermal vapour compression unit. Case3 replaces thermal vapour compression with mechanical vapour recompression. The layout and the pressure levels of the effects are kept. The steam leaving the third effect at about $61{ }^{\circ} \mathrm{C}$ is compressed mechanically to 75 ${ }^{\circ} \mathrm{C}$. As the $\Delta T$ is less than $18{ }^{\circ} \mathrm{C}$, a dynamic compressor (isentropic efficiency estimated to 0.7 ) is suitable and therefore selected (Figure 3b). In Case 4 all effects are realized in parallel and mechanical vapour recompression is integrated. The temperature difference for a mechanical vapour recompression is small $\left(<10^{\circ} \mathrm{C}\right)$. An isentropic efficiency for the compressor is estimated to 0.7 (Figure $3 \mathrm{c}$ ). The pressure levels of the five effects are adapted, so that all effects evaporates at about $70{ }^{\circ} \mathrm{C}$. In Case 5 the pressure of effects are modified and mechanical vapour recompressions are included: First the new temperature levels have to be defined. In order to keep the heat exchange surfaces of the effects (see Equation (1)) the temperature levels of effect 4 and 5 are reduced. The new temperature levels are $48{ }^{\circ} \mathrm{C}$ (effect 4 ) and $32{ }^{\circ} \mathrm{C}$ (effect5). Theoretically it could be possible to raise waste heat at $32{ }^{\circ} \mathrm{C}$ with a heat pump to satisfy a part of the heat demand in effect 1 . However, high temperature lifts makes such heat pump integration not optimal. The use of a successive mechanical vapour recompressions between the different effects has therefore been preferred (Figure 3d). The temperature of effect 5 is quite low. If technologically it is not feasible, it could also be possible to raise the temperature levels of all effects.

$Q=U * A *\left(T_{\text {vap }}-T_{\text {prod }}\right)$

The results of Table 2 are compared to the current energy consumption of the process. The saving potential of a well integrated process without any supplementary heat pumps or MVR is about $15 \%$. Heat pump or MVR integration will reduce the operating costs. In order to reduce the energy consumption, the effects can be modified (e.g. Case5). In Cases 2, 4 and 5, the heat pump or MVR can be integrated in the way that also heat from the condensation of the refrigeration cycle is used to heat up process streams. The 5 cases are compared regarding their estimated investment costs and related payback time (Table 3). To estimate the instantaneous power of heat hump or MVRs the mean value (heat load per tons of product) is multiplied by number of tons of products per year divided by the weekly total operating time of the evaporation unit. From selected quotations, the investment costs can be estimated related to the compressor power $\left(\dot{E}_{h p}\right.$ in $\left.[\mathrm{kW}]\right)$ with Equation (2) (installation factor $f$ supposed to be 1.5). In Case2, the process streams connected to 


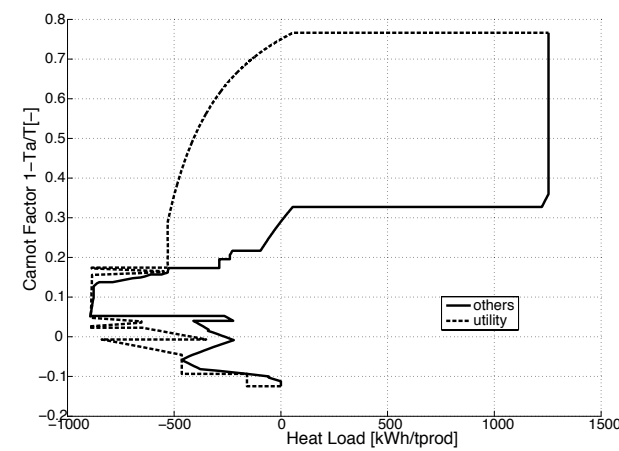

(a) Integrated composite curves Case2

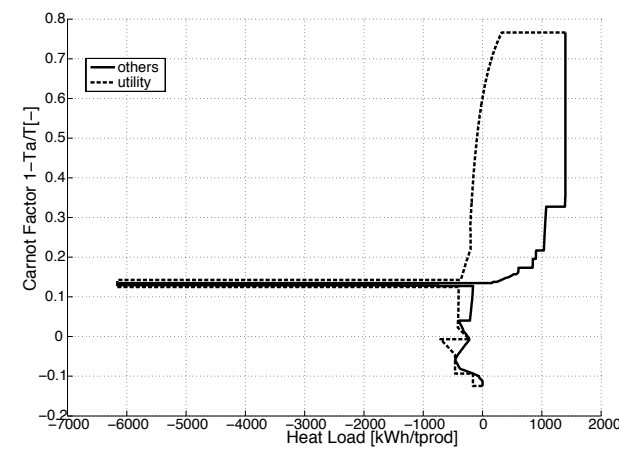

(c) Integrated composite curves Case 4

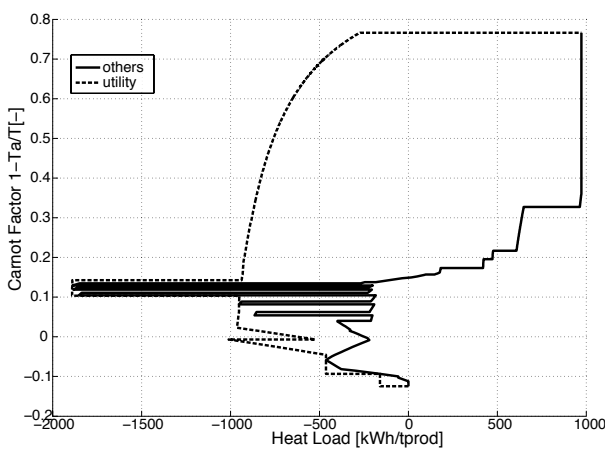

(b) Integrated composite curves Case3

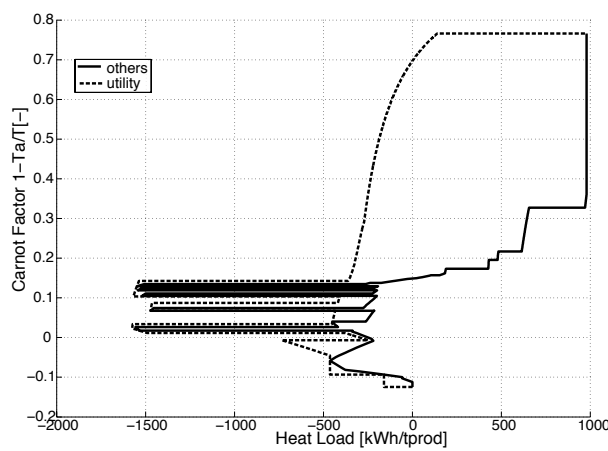

(d) Integrated composite curves Case5

Figure 3: Comparison of composite curves

the heat pump are not simultaneous. Thus, the investment can not be calculated without considering heat storage. In Table 3, two extreme cases have been evaluated: "max" corresponds to the peak power required by the heat source, while "mean" assumes that the heat source is stored and progressively upgraded leading to a more constant operation of the heat pump. Supplementary investment costs for heat storage tanks are not included.

$$
\text { Inv C }=f \cdot 1500 \cdot 160^{0.1} \cdot \dot{E}_{h p}^{0.9} \quad \text { [Euro] }
$$

\section{Comparison of results \& conclusions}

In all cases, the installation of a closed cycle heat pump or a mechanical vapour recompression reduces operating costs and $\mathrm{CO}_{2}$ emissions. The proper integration of heat pumps or MVRs changes the process pinch point location, allowing the heat recovery from the refrigeration cycle to preheat the process water and therefore leading to an even better integration and reduction of the mechanical power consumption. The investment costs are estimated and payback time can be roughly evaluated. However it has to be considered that the real investment costs depend strongly on a given case. Therefore the final decision has to be taken with concrete heat pump offers corresponding to the existing 
facilities and installations of the company.

Table 2: Comparison of utility integration

\begin{tabular}{|l|l|l|l|l|l|l|}
\hline & Unit & Case1 & Case2 & Case3 & Case4 & Case5 \\
\hline Operating Cost & {$[$ Euro/tprod] } & 107 & 96 & 97 & 93 & 75 \\
Saving potential & {$[\%]$} & -14.9 & -23.6 & -22.8 & -26 & -40.7 \\
\hline Fuel consumption & {$[\mathrm{kWh} /$ tprod] } & 2582 & 2157 & 2245 & 1935 & 1513 \\
Saving potential & {$[\%]$} & -10.8 & -25.5 & -22.5 & -33.1 & -47.8 \\
\hline Electricity consumption & {$[\mathrm{kWh} /$ tprod] } & 97 & 189 & 150 & 281 & 249 \\
Saving potential & {$[\%]$} & -50 & -2.6 & -22.6 & 44.8 & 28.4 \\
\hline Cooling water & {$[\mathrm{kWh} /$ tprod] } & 934 & 682 & 996 & 449 & 495 \\
\hline CO2 emissions & {$[\mathrm{kg} /$ tprod $]$} & 530 & 453 & 467 & 417 & 328 \\
Saving potential & {$[\%]$} & -12 & -24.8 & -22.5 & -30.8 & -45.5 \\
\hline
\end{tabular}

Table 3: Technologies

\begin{tabular}{|l|l|l|l|l|}
\hline & Case2 & Case3 & Case4 & Case5 \\
\hline$\dot{E}_{h p}[\mathrm{~kW}]$ & $372(\max ) 239($ mean $)$ & 241 & 698 & $297+136+152$ \\
\hline InvC [kEuro] & $771.6(\max ) 516.2(\operatorname{mean})$ & 519.9 & 1354.8 & 1285.1 \\
\hline Payback [Years] & $3.6(\max ) 2.4($ mean $)$ & 2.7 & 5.0 & 2.6 \\
\hline
\end{tabular}

\section{Acknowledgements}

The authors wish to thank ECLEER for supporting this research and collaborating in its realization.

\section{References}

Becker H., Girardin L. and Maréchal F., 2010, Energy integration of industrial sites with heat exchange restrictions, European Symposium on Computer Aided Process Engineering - ESCAPE 20, 1141-1146.

Becker H., Maréchal F. and Vuillermoz A., 2011, Process integration and opportunity for heat pumps in industrial processes, International Journal of Thermodynamics, ECOS 2009 special issue, accepted.

Kapustenko P. O., Ulyev L. M., Boldyryev S. A. and Garev A. O., 2008, Integration of a heat pump into the heat supply system of a cheese production plant, Energy 33, 882889.

Linnhoff B. and Townsend D., 1983, Heat and power networks in process design. part 1: Criteria for placement of heat engines and heat pumps in process networks, AIChE Journal 29 (5), 742-748.

Pavlas M., Stehlík P., Oral J., Klemeš J., Kim J. and Firth B., 2010, Heat integrated heat pumping for biomass gasification processing, Applied Thermal Engineering 30, 30-35.

Wallin E. and Berntsson T., 1994, Integration of heat pumps in industrial processes, Heat Recovery Systems \& CHP 14 (3), 287-296. 